\title{
Peritoneal Dialysis in the Reduction of Blood Ammonia Levels in a Case of Hyperammonaemia
}

\author{
J. T. HERRIN` and D. A. MCCREDIE \\ From the Department of Paediatrics, University of Melbourne, \\ and Royal Children's Hospital, Parkville, Australia
}

Four disease entities associated with hyperammonaemia and corresponding to lack of each of the specific enzymes required in the Krebs Henseleit urea cycle have now been reported (Russell et al., 1962; Freeman et al., 1964). A closely allied condition, lysine intolerance, where lysine competes with arginine for arginase has also recently been described (Colombo et al., 1964). Patients with these conditions have extremely high blood and CSF levels of ammonia, frequently much higher than in hepatic coma. The acute neurological sequence of spasticity, confusion, and coma during hyperammonaemic crises in these patients is analogous to that in hepatic coma precipitated by ingestion of protein in cirrhotic patients with an Eck fistula. Chronic ammonia intoxication, on the other hand, is characterized by periodic vomiting, deterioration of intelligence, progressive spasticity, and cerebral atrophy. Both haemodialysis and peritoneal dialysis have been shown to be of limited use in the treatment of ammonia intoxication in hepatic failure (Kiley et al., 1958; Krebs and Flynn, 1967; Maxwell et al., 1959; Nienhuis, 1966). Increase in blood ammonia is commonly associated with hepatic coma but is frequently not the precipitating cause. This may explain why reduction in ammonia levels by dialysis has not been more successful (Brown, 1967).

This paper reports a patient with hyperammonaemia due to deficiency of ornithine transcarbamylase in whom peritoneal dialysis was of considerable value in reducing blood ammonia levels.

\section{Case Report}

Full clinical and biochemical details of the patient are reported elsewhere in this issue (Hopkins et al., 1969) and are here given in summary.

The patient, a female aged 18 months, had had two

Received October 7, 1968.

* Present address: Shriner's Burns Institute, Massachusetts General Hospital, Boston, Mass., U.S.A. previous hospital admissions because of vomiting, irritability, and failure to maintain normal physical and mental development. At 13 months hyperammonaemia was suspected and blood ammonia was found to be $428 \mu \mathrm{g} . / 100 \mathrm{ml}$. and $734 \mu \mathrm{g} . / 100 \mathrm{ml}$. on 2 estimations (normal range for adults $<60 \mu \mathrm{g} . / 100 \mathrm{ml}$.). A low protein diet of high caloric and essential amino acid content $(1.5 \mathrm{~g}$. protein $/ \mathrm{kg}$. per day) resulted in marked clinical improvement. Blood ammonia fell to $100 \mu \mathrm{g} . / 100 \mathrm{ml}$. over the following 2 weeks and subsequently to normal levels (26 and $56 \mu \mathrm{g} . / 100 \mathrm{ml}$.) over the next 2 months.

At 18 months an open liver biopsy was parformed under nitrous oxide and halothane anaesthesia. Her condition remained satisfactory for 12 hours after operation, but rapidly deteriorated over the ensuing 12 hours. During this time she took only small quantities of oral glucose and water, and blood ammonia rose from $72 \mu \mathrm{g} . / 100 \mathrm{ml}$. immediately after operation to $1000 \mu \mathrm{g}$. $/ 100 \mathrm{ml}$. after 24 hours. This was associated with dehydration, acidosis, intermittent convulsions, and profound coma. Intravenous therapy was started with $5 \%$ dextrose in $\frac{1}{4}$ isotonic saline and added bicarbonate. After rehydration blood ammonia fell to $670 \mu \mathrm{g} . / 100$ $\mathrm{ml}$., but by the next day this had risen to $1970 \mu \mathrm{g} . / 100$ $\mathrm{ml}$. despite a protein sparing regimen with intravenous fructose and anabolic steroids.

Peritoneal dialysis was started 54 hours after operation, using standard ( $1.5 \%$ dextrose) dialysis fluid containing $\mathrm{KCl} 6 \mathrm{mEq} / \mathrm{l}$. and exchanges of $400 \mathrm{ml}$. (i.e. $40 \mathrm{ml} . / \mathrm{kg}$.) in 1-hourly cycles. The effect on blood ammonia is shown in the Fig. Blood ammonia had fallen to 800 $\mu \mathrm{g} . / 100 \mathrm{ml}$. after 4 hours, at which time the child was responding to painful stimuli. 12 hours later the level had fallen to $640 \mu \mathrm{g} . / 100 \mathrm{ml}$., with further improvement in conscious state. She now made spontaneous purposeful movements and was able to tolerate a short period without assisted respiration. However, deterioration occurred, she became cyanosed and acidotic, and once again required assisted respiration. Dialysis was continued for a total of 36 exchanges over 36 hours, by which time blood ammonia had fallen to $330 \mu \mathrm{g}$. $100 \mathrm{ml}$., a level previously unassociated with coma in this patient. Dialysis was suspended with the catheter left in situ, but blood ammonia rapidly rose to 780 
$\mu \mathrm{g} . / 100 \mathrm{ml}$. and dialysis was restarted. No clinical improvement was observed after her second deterioration and she died 10 hours later. 5\% dextrose in $\frac{1}{4}$ isotonic saline was continued at approximately maintenance rates during the dialysis.

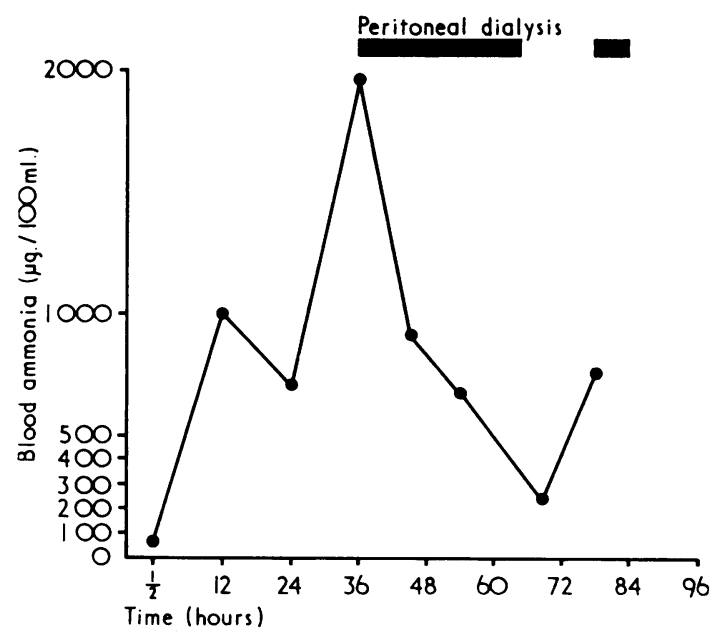

FIG. Effect of peritoneal dialysis on blood ammonia levels. The abscissa represents time after open liver biopsy.

\section{Discussion}

Ammonia intoxication in the body occurs most commonly in hepatic failure when ammonia absorbed from the gut bypasses the liver due to porto-systemic shunting. Russell et al. (1962) reported 2 cases of hyperammonaemia due to ornithine transcarbamylase deficiency, where blood ammonia and CSF ammonia levels of $980 \mu \mathrm{g} .100$ $\mathrm{ml}$. and $360 \mu \mathrm{g} . / 100 \mathrm{ml}$., respectively, were found. These are much higher than the levels usually considered toxic in hepatic coma.

Both haemodialysis and peritoneal dialysis have been used to treat ammonia intoxication in hepatic failure. Kiley et al. (1958) showed that haemodialysis with a Kolff system removed blood ammonia, and improvement in conscious state followed some hours later. Nienhuis (1966) showed clinical improvement which paralleled fall in blood ammonia levels in a patient who recovered from hepatic coma after peritoneal dialysis, and Maxwell et al. (1959) showed temporary improvement in their patient with hepatic coma though blood ammonia levels were not estimated. Krebs and Flynn (1967) used peritoneal dialysis to prevent ammonia intoxication during exchange transfusion of a patient with acute hepatic failure. They were able to maintain blood ammonia levels at $200 \mu \mathrm{g} . / 100 \mathrm{ml}$. even though dialysate levels were very low and ammonia levels of stored blood high.

In our case peritoneal dialysis was chosen in view of the patient's grave condition and the problems of cannulation in the very young. In addition, the relatively greater peritoneal membrane area makes peritoneal dialysis more efficient in a child (Esperanca and Collins, 1966). It was possible to produce an initial fall in blood ammonia level and with continuing dialysis to maintain a steady state (see Fig.).

Return to consciousness lagged behind the fall in blood level as in those cases reported by Kiley et al. (1958). After an initial rapid fall, blood ammonia fell more slowly to $300 \mu \mathrm{g} . / 100 \mathrm{ml}$. This demonstrated the possibility of maintaining such a level of blood ammonia in the face of a persisting high rate of ammonia production, as evidenced by the rapid rise in blood ammonia from 300 to $780 \mu \mathrm{g} . / 100 \mathrm{ml}$. when dialysis was suspended.

In previously reported cases of hepatic coma treated by dialysis ammonia levels have been much lower and dialysis less efficient. The higher levels present in our case would lead to more efficient removal of ammonia initially, owing to the high concentration gradient. Though direct measurement of ammonia in dialysis fluid was not performed, a Berthelot (phenolic hypochlorite) reaction was performed on dialysis fluid, and showed removal of large amounts of ammonia and glutamine nitrogen in the early stages, with a fall to much lower levels as the dialysis continued.

The rapid fall in blood ammonia levels in the initial phase may have been influenced by the absorption of glucose from the dialysis fluid (blood glucose rising to $340 \mathrm{mg} . / 100 \mathrm{ml}$. at this stage). Brown et al. (1967) have shown a correlation between ammonia and glucose metabolism in patients with liver disease, particularly those with a portosystemic shunt. They noted a fall in blood ammonia associated with a rise in blood glucose concentration, and suggested that this was due to utilization of ammonia by increased activity of the tricarboxylic acid cycle. This could act by producing more aspartate to combine with citrulline, or by increased conversion of $\alpha$-ketoglutaric acid to glutamic acid and glutamine. The deficiency of ornithine transcarbamylase in our patient would limit the amount of citrulline available and make this first mechanism unlikely to be contributory.

However, the initial fall in blood ammonia levels could represent the combination of peri- 
toneal clearance and increased conversion of ammonia via $x$-ketoglutaric acid.

\section{Summary and Conclusion}

An 18-month-old infant with hyperammonaemia due to ornithine transcarbamylase deficiency is described in whom peritoneal dialysis rapidly reduced blood ammonia from extremely high levels to lower levels which had previously not been associated with coma. At these levels, similar to those seen in hepatic coma (i.e. approximately $300 \mu \mathrm{g} . / 100 \mathrm{ml}$. ), a stable state was maintained using peritoneal dialysis even in the face of continuing high ammonia production.

Though removal of ammonia at lower levels is less efficient, peritoneal dialysis may be of value in the control of a hyperammonaemic crisis, as in this case, or where the condition leading to the high blood ammonia level is reversible.

The authors wish to thank Dr. T. G. Maddison for permission to report details of this case under his care, Mr. J. Hoban, St. Vincent's Hospital, for blood ammonia levels, and members of the Biochemistry Department, Royal Children's Hospital, for biochemical studies.

\section{REFERENCES}

Brown, H. (1967). Treatment of hepatic failure and coma. F. Amer. med. Ass., 201, 547.

—, Brown, M. E., Covelli, V. H., and McDermott, W. V., Jr. (1967). Ammonia and glucose metabolism in liver failure. ibid., 201, 873.

Colombo, J. P., Richterich, R., Donath, A., Spahr, A., and Rossi, E. (1964). Congenital lysine intolerance with periodic ammonia intoxication. Lancet, 1, 1014.

Esperanca, M. J., and Collins, D. L. (1966). Peritoneal dialysis efficiency in relation to body weight. $f$. pediat. Surg., $1,162$.

Freeman, J. M., Nicholson, J. F., Masland, W. S., Rowland, L. P., and Carter, S. (1964). Ammonia intoxication due to a congenital defect in urea synthesis. F. Pediat., 65, 1039.

Hopkins, I. J., Connelly, J. F., Dawson, A. G., Hird, F. S. R., and Maddison, T. G. (1969). Hyperammonaemia due to ornithine transcarbamylase deficiency. Arch. Dis. Childh., 44, 143.

Kiley, J. E., Pender, J. C., Welch, H. F., and Welch, C. S. (1958). Ammonia intoxication treated by hemodialysis. New Engl. f. Med., 259, 1156.

Krebs, R., and Flynn, M. (1967). Treatment of hepatic coma with exchange transfusion and peritoneal dialysis. f. Amer. med. Ass., 199, 430.

Maxwell, M. H., Rockney, R. E., Kleeman, C. R., and Twiss, M. R. (1959). Peritoneal dialysis 1 . Technique and applications. ibid., 170, 917 .

Nienhuis, L. I. (1966). Clinical peritoneal dialysis. Arch. Surg., 93, 643.

Russell, A., Levin, B., Oberholzer, V. G., and Sinclair, L. (1962). Hyperammonaemia. A new instance of an inborn enzymatic defect of biosynthesis of urea. Lancet, 2, 699.

Correspondence to Dr. D. A. McCredie, Department of Paediatrics, Royal Children's Hospital, Flemington Road, Parkville N.2, Melbourne, Victoria, Australia. 